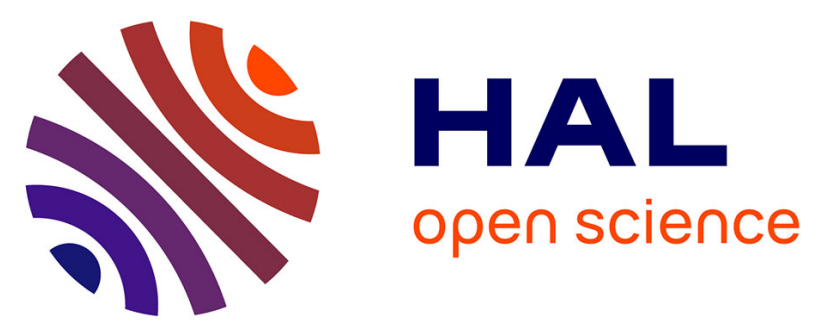

\title{
Just the tip of the iceberg: difficulties in assessing and managing extreme obesity in routine clinical care
}

Christine Poitou, Margot Denis, Zeina Chakhtoura, Catherine Uzan, Maryam Nikpayam, Jean-Michel Oppert

\section{- To cite this version:}

Christine Poitou, Margot Denis, Zeina Chakhtoura, Catherine Uzan, Maryam Nikpayam, et al.. Just the tip of the iceberg: difficulties in assessing and managing extreme obesity in routine clinical care. European Journal of Clinical Nutrition, 2018, 72 (3), pp.452-454. 10.1038/s41430-017-0056-z . hal01826572

\section{HAL Id: hal-01826572 \\ https: / hal.sorbonne-universite.fr/hal-01826572}

Submitted on 29 Jun 2018

HAL is a multi-disciplinary open access archive for the deposit and dissemination of scientific research documents, whether they are published or not. The documents may come from teaching and research institutions in France or abroad, or from public or private research centers.
L'archive ouverte pluridisciplinaire HAL, est destinée au dépôt et à la diffusion de documents scientifiques de niveau recherche, publiés ou non, émanant des établissements d'enseignement et de recherche français ou étrangers, des laboratoires publics ou privés. 


\title{
Just the tip of the iceberg: difficulties in assessing and managing extreme obesity in routine clinical care
}

\author{
Christine Poitou ${ }^{1,2,3} \cdot$ Margot Denis ${ }^{1,2,3} \cdot$ Zeina Chakhtoura ${ }^{2,3,4} \cdot$ Catherine Uzan ${ }^{2,5,6,7} \cdot$ Maryam Nikpayam ${ }^{2,5,7} \cdot$ \\ Jean-Michel Oppert ${ }^{1,2,3}$
}

\begin{abstract}
As obesity prevalence increases worldwide, healthcare professionals are often faced with challenging cases associated with massive obesity. A 33-year-old woman (weight $342 \mathrm{~kg}$, body mass index $=100 \mathrm{~kg} / \mathrm{m}^{2}$ ) presented with respiratory failure, limb edema and ascites. Abdominal CT scan became feasible after initial weight loss and showed a large pelvic mass in contact with the left ovary. The surgical removal performed despite a high-risk profile led to the diagnosis of a giant mucinous borderline tumor whose growth was due to delayed care and responsible for multiple severe complications: sepsis, anemia, esophagitis, constipation, anorexia due to mechanical compression, undernutrition, sarcopenia and lower limb edema contributing to a severe disability. After 7 months under specialized care, her weight decreased to $180 \mathrm{~kg}$, complications were treated and disability improved. This case, showing that, despite barriers, a multidisciplinary approach makes quality of care possible even in massively obese patients, is an educational example to reduce stigma.
\end{abstract}

A 33-year-old woman with extreme obesity (weight $342 \mathrm{~kg}$, body mass index $=100 \mathrm{~kg} / \mathrm{m}^{2}$ ) was admitted to the emergency department with respiratory failure, limb edema and ascites. Her weight had increased over the last months with worsening of her general health status. As her corpulence limited physical examination and excluded standard imaging investigations, she was empirically treated with

Christine Poitou and Margot Denis contributed equally to this work.

Christine Poitou

christine.poitou-bernert@aphp.fr

1 Department of Nutrition, Assistance Publique-Hôpitaux de Paris (AP-HP), Pitié-Salpêtrière Hospital, Paris, France

2 Sorbonne Universités UPMC Univ, Paris, France

3 Institute of Cardiometabolism and Nutrition (ICAN), Paris, France

4 Department of Endocrinology and Reproductive Medicine, Assistance Publique-Hôpitaux de Paris (AP-HP), Pitié-Salpêtrière Hospital, Paris, France

5 Department of Breast and Gynecologic Surgery, Assistance Publique-Hôpitaux de Paris (AP-HP), Pitié-Salpêtrière Hospital, Paris, France

6 Inserm U938, Paris, France

7 Institut universitaire de cancérologie (IUC), Paris, France anticoagulants and antibiotics for a possible pulmonary embolism and pneumonia. She also received a loop diuretic and continuous positive airway pressure was initiated. After initial improvement of her respiratory status, she was transferred to a post-acute rehabilitation department. Ascites remained unchanged despite draining and diuretic treatment. After 5 months under medical supervision and following a controlled diet, she had lost a large amount of weight $(-92 \mathrm{~kg})$ but remained disabled, bedridden and needed assistance from 6 professionals for routine hygienic care.

She was referred to our obesity clinic for specialized nutritional care and etiological investigation of ascites. Ascites aspiration revealed a liquid exudate without bacterial pathogens. There was no evidence for hepatitis, cardiac or renal failure. Abdominal and pelvic intra-vaginal ultrasound performed at the patient's bed did not show any effusion in the Douglas pouch or behind the liver. However, we observed a very large abdominal mass of a multicystic nature. Because of technical difficulties, the ultrasonographer could not exclude or confirm an ovarianrelated disease. Although she had experienced substantial weight loss, the patient's body shape still prevented performing standard imaging, such as computed tomography (CT) or magnetic resonance imaging (MRI). A duodenal echo-endoscopy and a proctoscopy were performed and did 


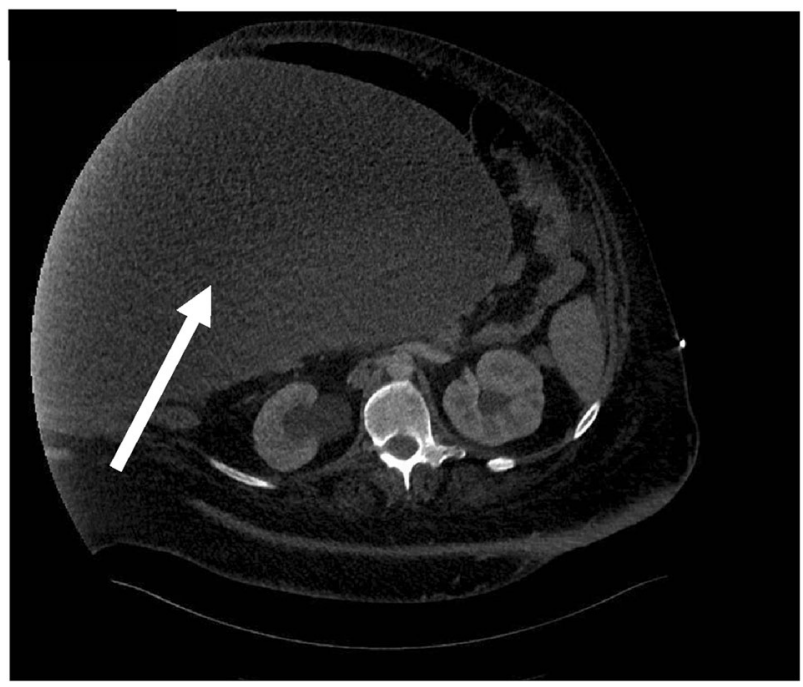

Fig. 1 CT scan of the pelvic region in a woman with extreme obesity. The white arrow indicates a large pelvic mass measuring $40 \times 24 \times 40$ $\mathrm{cm}$

not show any finding in favor of a gastrointestinal or pancreatic tumor. There were no sign of peritoneal carcinosis either. The marker CA 19-9 was increased $(800 \mathrm{U} / \mathrm{ml}, N<$ 60 ) and CA125 was normal. Therefore, an ovarian tumor was the most probable diagnosis. Reviewing the case with the gynecological surgeon led to a decision to operate despite obvious surgical difficulties and a high-risk profile for anesthesia and surgical-related complications in this patient with extreme obesity.

Owing to further patient weight loss, a CT scan became feasible before surgery. It confirmed the presence of a large pelvic cystic mass measuring $40 \times 24 \times 40 \mathrm{~cm}$, in contact with the left ovary (Fig. 1). The liver appeared normal. No peritoneal carcinosis was observed. Surgical removal of this mass was performed by laparotomy during a $6 \mathrm{~h}$ surgical procedure. Seventeen liters of gelatinous liquid were removed from the mass, which originated from the left ovary. The excised mass weighed $3 \mathrm{~kg}$. Pathological examination concluded the mass was a mucinous borderline tumor without invasive implants. Borderline ovarian tumors (BOTs) account for $10-15 \%$ of epithelial tumors. Mucinous BOTs are the second most common tumor type (after serous) and account for 35 to $45 \%$ of BOTs. These tumors are usually large, unilateral, composed of multiple cystic spaces with variable diameter [1]. BOTs occur in women around the age of 40 years. The prognostic factors include characteristics of the tumor (stage, peritoneal implants), type of surgery, preoperative CA125, bilateral forms and age, but not obesity.

The major growth in size of that tumor was due, at least in part, to delayed care in an extreme form of obesity and was responsible for multiple severe complications. First, it was probably infected after multiple drains of ascites, and responsible for three episodes of meti-S Staphylococcus aureus sepsis. Second, the patient had several digestive symptoms likely due to mechanical compression from the tumor, which included esophagal reflux with erosive esophagitis, severe constipation with several sub-occlusive episodes and anorexia. These symptoms led to undernutrition with global edemas which required enteral nutrition over the course of a few months. The patient also exhibited severe anemia requiring several blood transfusions. Third, pelvic compression led to aggravation of lower limb venous insufficiency and lymphedema. This state of extreme obesity, associated with undernutrition and sarcopenia, was responsible for disability despite the young age of the patient.

After 7 months of hospitalization under specialized care, albuminemia was normalized and the patient's weight was $180 \mathrm{~kg}$. She could sit alone and required only 2 people helping her with the toilet.

This case illustrates how extreme obesity may mask other comorbidities and highlights some of the difficulties encountered in assessment and management of severely obese patients. First, obese patients are vulnerable to multiple forms of weight bias and stigmatization, and this applies particularly to healthcare settings [2]. Due to past negative experiences with health professionals, these patients may avoid or postpone medical care and present with more advanced and thus more difficult to treat conditions. They can also withdraw from full participation in proposed treatments with reduced adherence to treatment and counseling. In this context, even benign diseases can lead to severe complications and injuries. Second, corpulence exhibited during severe obesity poses a tremendous challenge to clinical diagnosis and treatment such as drug titration especially for anticoagulants and antibiotics but also for transportation and explorations including imaging [3]. As such, conventional MRI and CT scan devices are limited by the gantry size and the table weight limits.

Given increasing obesity rates worldwide [4], especially increasing rates of massively obese cases, and in order for these patients to receive adequate care in an equitable fashion [5], the healthcare delivery systems need to adapt and training/education in obesity management need to be developed for healthcare professionals. Adequate transportation and equipment, management and treatment need to be adapted to provide necessary resources at all levels of care to patients with morbid obesity.

Acknowledgements The authors would like to thank Dr T. Swartz for English editing. 


\section{Compliance with ethical standards}

Conflict of interest The authors declare that they have no conflict of interest.

\section{References}

1. Morice P, Uzan C, Fauvet R, Gouy S, Duvillard P, Darai E. Borderline ovarian tumour: pathological diagnostic dilemma and risk factors for invasive or lethal recurrence. Lancet Oncol. 2012;13: e103-e115. P
2. Phelan SM, Burgess DJ, Yeazel MW, Hellerstedt WL, Griffin JM, van Ryn M. Impact of weight bias and stigma on quality of care and outcomes for patients with obesity. Obes Rev. 2015;16:319-26.

3. Allison DB, Nathan JS, Albu JB, Heymsfield SB, Duprat LJ, PiSunyer FX. Measurement challenges and other practical concerns when studying massively obese individuals. Int $\mathrm{J}$ Eat Disord. 1998;24:275-84.

4. NCD Risk Factor Collaboration (NCD-RisC), Trends in adult body-mass index in 200 countries from 1975 to 2014: a pooled analysis of 1698 population-based measurement studies with $19 \cdot 2$ million participants. Lancet. 2016;387:1377-96.

5. Le NT, Robinson J, Lewis SJ. Obese patients and radiography literature: what do we know about a big issue? J Med Radiat Sci. 2015;62:132-41. 